\title{
What Can Twitter Tell Us about Skin Cancer Communication and Prevention on Social Media?
}

\author{
Carina Vasconcelos Silva ${ }^{a}$ Dilki Jayasinghe ${ }^{a}$ Monika Janda ${ }^{a}$ b \\ ${ }^{a}$ Centre for Health Services Research, Faculty of Medicine, The University of Queensland, Brisbane, QLD, Australia; \\ ${ }^{b}$ School of Public Health and Social Work, Institute of Health and Biomedical Innovation, Queensland University of \\ Technology, Brisbane, QLD, Australia
}

\section{Keywords}

Skin cancer · Social media · Health promotion - Twitter communication patterns

\begin{abstract}
Background: Skin cancer places a substantial burden on the health system in Australia. The modernisation of skin cancer prevention interventions by using social media may enhance their contemporary reach and relevance, especially among the youth. This study aimed to analyse Twitter posts in Australia to establish a baseline of skin cancer and sunrelated communication trends. Methods: Tweets posted over the summer of 2018/2019 relating to relevant keywords and hashtags such as "slipslopslap" and "sunscreen" were analysed using quantitative and qualitative methods. The number of tweets, related communication patterns, and possible factors for sudden changes in tweet volume were studied. Results: Results showed that Australians are using Twitter to communicate about their sun-related and skin cancer experiences and to share advice and information on this matter. Overall, Australians use Twitter more frequently to talk about sunscreen (number of tweets between December 2018 and February $2019=5,842)$ and/or skin cancer $(n=$ $3,936)$, but not so often to communicate about other sun-
\end{abstract}

protective behaviours ( $n=1,972$ ) or skin cancer prevention campaigns ( $n=108$ ). The number of tweets is greatly affected by the increase in temperature. Celebrities, non-healthrelated organisations with a high number of followers, and individuals sharing their own skin cancer experiences achieve a substantial number of likes and retweets and thus influence on Twitter regarding skin cancer-related communication. Conclusions: The results allow deeper understanding of important determinants for effective social media use for health promotion and public health messaging in the future. Linking tweets with temperature, sharing by celebrities or non-health-related organisations and individuals with a high following can all contribute to greater spread of skin cancer and sun-related messages.

๑) 2020 S. Karger AG, Basel

\section{Introduction}

Worldwide, skin cancer is a significant public health concern. Its incidence continues to increase, to now being one of the most commonly diagnosed cancers in many

This article is part of the Nevi Article Series

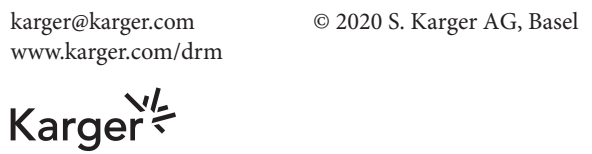

Prof. Monika Janda

Centre for Health Services Research, The University of Queensland

Level 2, Building 33, Princess Alexandra Hospital

Woolloongabba, QLD 4102 (Australia)

m.janda@uq.edu.au 


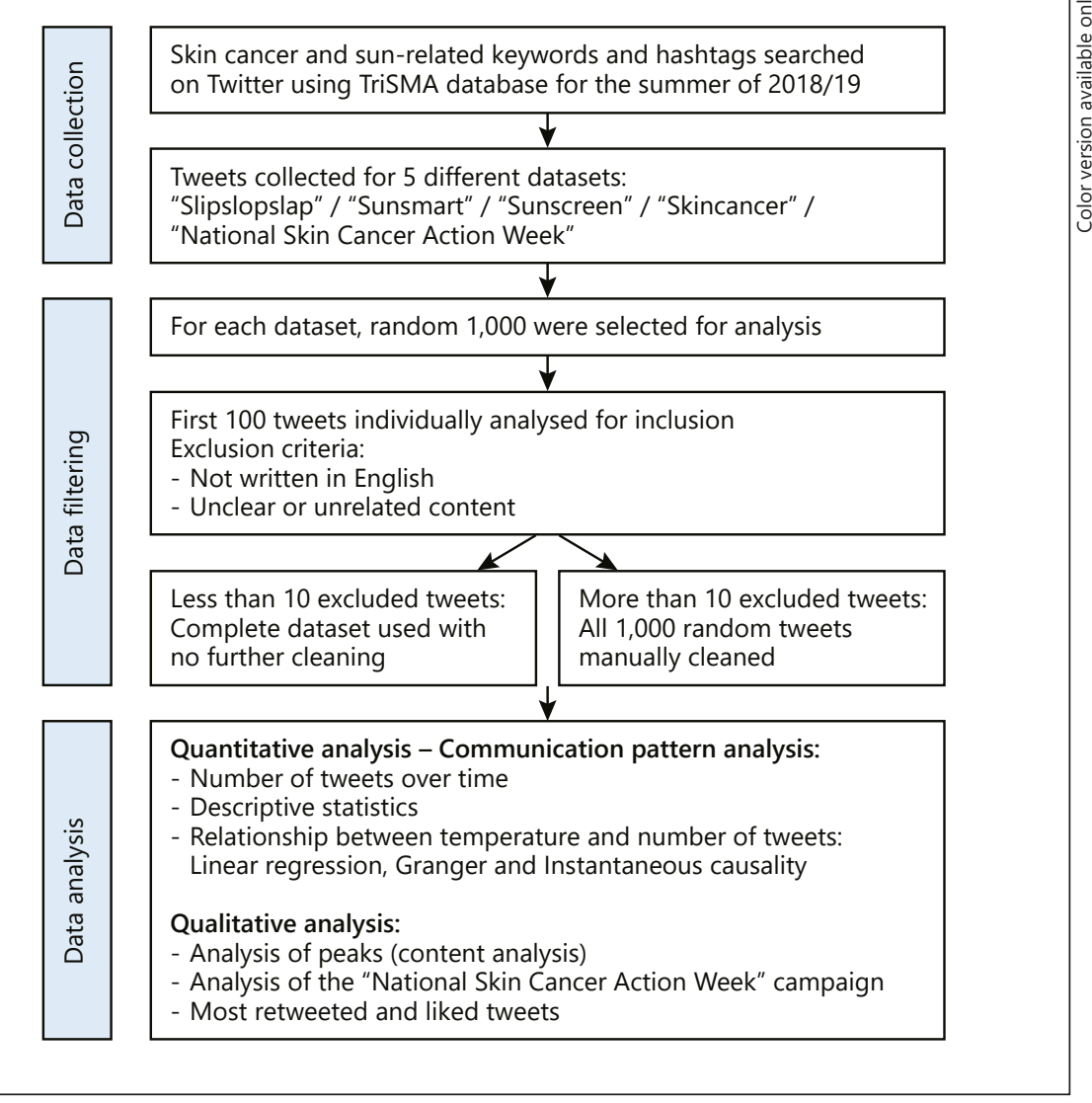

Fig. 1. Flowchart of Methods.

countries of the world [1]. The age-standardised incidence rate of melanoma in Australia is approximately eleven times higher compared to the world average [2] and it is the most common cancer diagnosed among young people [3]. Australia has a remarkably long history of skin cancer prevention campaigns, such as Slip Slop Slap!, which were successful in creating a community that is often aware of the importance of adopting safe sun behaviour [4]. Nevertheless, sun protection behaviours are still far from being ideal and young people, in particular, are the group least compliant [5-7].

Advances in technology require health promotion interventions to follow the actual media consumption patterns of the population, with a move away from traditional media consumption, such as television [8], to the predominant use of digital technologies. Approximately 99\% of Australians aged 18-29 years use social media [9] and evidence suggests that it has become an important part of their daily life [10], including seeking information about health $[11,12]$. Social media thus offers unique opportunities to reach a large proportion of this hard-to-reach group and potential for health promotion interventions $[13,14]$.
Innovative "infoveillance" methods for public health surveillance are becoming increasingly available and applied for the real-time analysis of health-related communication patterns on the Internet [15]. Social networking analysis of Twitter data has been used to study healthrelated communication patterns and trends on a wide range of topics including influenza [16], obesity [17], and cancer [18]. It has also been used to analyse the reach of health promotion campaigns $[19,20]$, including for skin cancer prevention in the USA [21]. Such analyses could also be informative for health promotion planning in Australia.

Applying both quantitative and qualitative methods, the main objective of this study was to analyse commonly used skin cancer and sun-related Twitter keywords and hashtags (\#) over the summer of 2018/2019.

The study was intended to answer the following questions:

- What are the number, related communication patterns, and content of tweets being shared regarding skin cancer and sun-related communication over the summer months in Australia? 
Table 1. Tweets gathered and excluded and descriptive statistics

\begin{tabular}{|c|c|c|c|c|c|c|}
\hline \multicolumn{4}{|c|}{ Before cleaning } & \multicolumn{3}{|c|}{ After cleaning ( 1,000 random tweets analysed) } \\
\hline & $\begin{array}{l}\text { tweets } \\
\text { retrieved }\end{array}$ & $\begin{array}{l}\text { manually } \\
\text { cleaned }\end{array}$ & excluded & tweets/day & minimum & maximum \\
\hline Slipslopslap & 1,068 & no & & $10(5-14)$ & 1 & 45 \\
\hline Sunsmart & 1,972 & no & & $9(6-15)$ & 0 & 54 \\
\hline Sunscreen & 5,842 & yes & 175 & $9(7-13)$ & 2 & 57 \\
\hline Skincancer & 3,936 & yes & 107 & $10(6-14)$ & 2 & 33 \\
\hline NSCAW & 109 & yes & 1 & $3(1-10)$ & 1 & 20 \\
\hline
\end{tabular}

Data are presented as $n$ or median (IQR), as appropriate. NSCAW, National Skin Cancer Action Week.

- Is temperature a main factor influencing changes in communication patterns?

- What is the reach of tweets concerning the National Skin Cancer Action Week?

- Which are the most retweeted and liked tweets and what may have motivated this?

\section{Methods}

For further details, see the online supplementary material (see www.karger.com/doi/10.1159/000506458 for all online suppl. material) (Fig. 1; Table 1) [20, 22-25].

\section{Results}

\section{Number of Tweets}

The hashtag and keyword search identified a total of 12,927 tweets available for analysis within the 3 summer months of 2018/2019 and the National Skin Cancer Action Week (NSCAW). The total number of tweets gathered for each dataset and related descriptive statistics are described in Table 1. The datasets "sunscreen" and "skincancer" contained the highest number of retrieved tweets: 5,842 for sunscreen and 3,936 for skin cancer. There were 1,068 tweets gathered for "slipslopslap" and 1,972 for "sunsmart." Only 108 tweets were collected directly relating to the NSCAW campaign.

\section{Communication Patterns and Relationship with Temperature}

Figure 2 presents the distribution of the number of tweets over time for each dataset. It can be noticed that peaks seem to occur in similar patterns during the sum- mer. For example, a significant peak occurred on January 25, 2019, in all the datasets. Except for "skincancer," all datasets reached their maximum number of tweets during that summer on that day. For sun smart-related tweets, the number of tweets posted on the 25th of January reached six times the median number of tweets per day: median $=9(6-15)$. Figure 2 (yellow line) also presents the average maximum temperature in Sydney and Melbourne per day during the summer: median $=26.75^{\circ} \mathrm{C}$ $\left(24.75-29.70^{\circ} \mathrm{C}\right)$.

Figure 2 highlights that the number of tweets increased on days with high maximum temperatures, suggesting a possible relationship. On January 25, 2019, when the maximum volume of tweets occurred across multiple datasets, Melbourne experienced its maximum temperature that summer $\left(43^{\circ} \mathrm{C}\right)$, and New South Wales went through a heatwave on the same weekend.

Linear regression analysis confirmed a significant positive correlation between daily maximum temperature in Sydney and Melbourne and number of tweets per day for all datasets (Table 2). While Granger causality indices did not support significant relationships between temperature and number of tweets, instantaneous causality analysis retained a significant association between temperature and "slipslopslap" and "sunscreen" tweets.

\section{Qualitative Analysis}

\section{Content Analysis}

For each dataset, representative tweets from the 2 days with the highest volume are presented in Table 3 . Content analysis identified three main themes: "health information," "health advice," and "health-related expressiveness." "Health information" tweets shared new treatments or new results, such as: "Sun safety professionals now recommend individuals apply sunscreen every day." 
Table 2. Relationship between number of tweets and average daily maximum temperature in Sydney and Melbourne

\begin{tabular}{|c|c|c|c|c|c|}
\hline \multirow[t]{2}{*}{ Dataset } & \multicolumn{3}{|c|}{ Simple linear regression } & \multicolumn{2}{|l|}{ Causality ( $p$ value) } \\
\hline & $\begin{array}{l}\text { Durbin- } \\
\text { Watson }\end{array}$ & $\begin{array}{l}\text { coefficient (B) and } \\
\text { its significance }\end{array}$ & $R^{2}$ & Granger causality & $\begin{array}{l}\text { instantaneous } \\
\text { causality }\end{array}$ \\
\hline Slipslopslap & 1.59 & $1.01(p<0.001)$ & 0.217 & 0.069 & 0.003 \\
\hline Sunsmart & 1.48 & $0.78(p<0.001)$ & 0.130 & 0.318 & 0.306 \\
\hline Sunscreen & 1.37 & $1.12(p<0.001)$ & 0.257 & 0.170 & 0.002 \\
\hline Skincancer & 1.76 & $0.57(p=0.007)$ & 0.080 & 0.414 & 0.324 \\
\hline
\end{tabular}

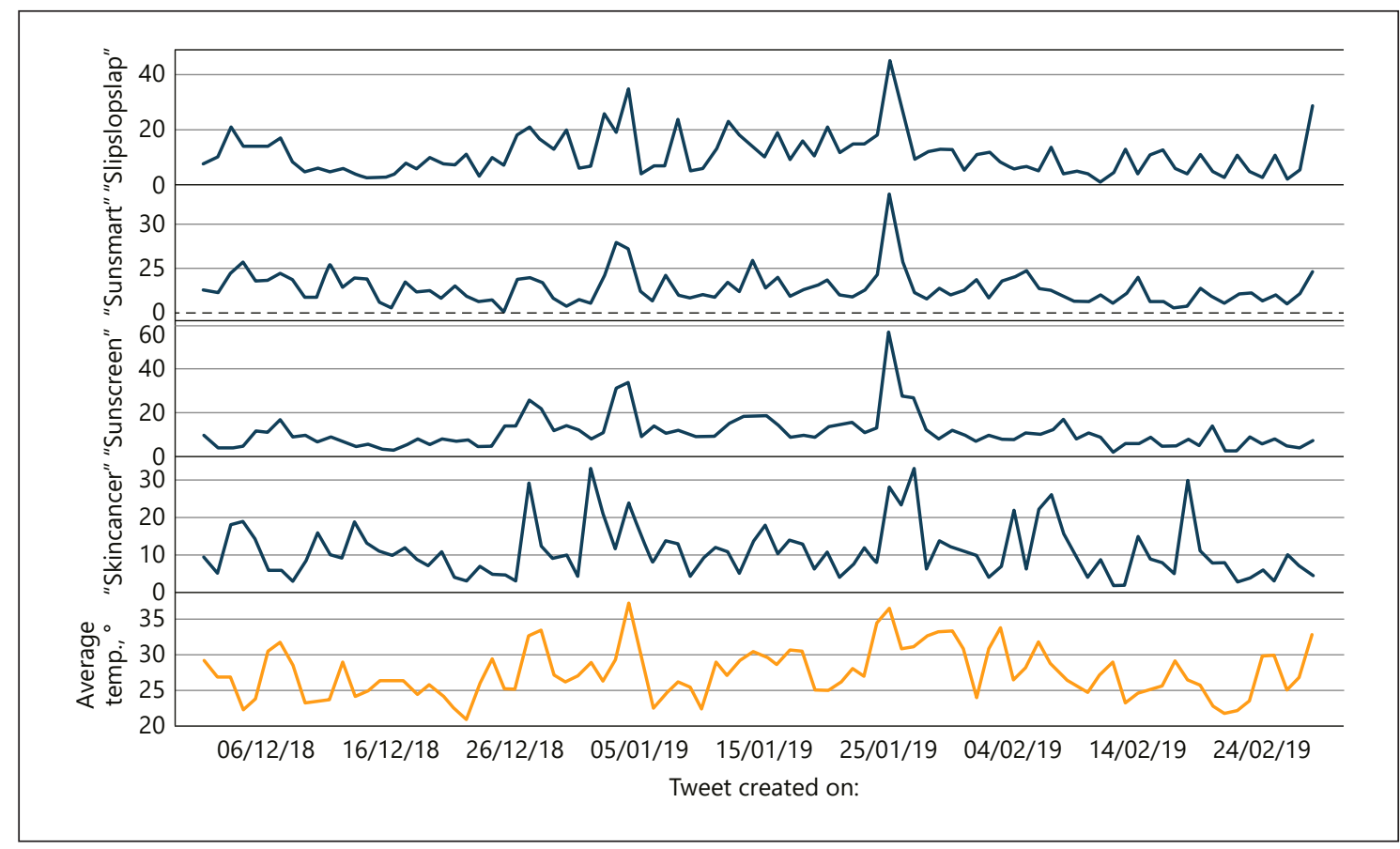

Fig. 2. Distribution of the number of tweets and maximum temperature over time. Upper panels: daily number of tweets for each dataset (blue lines). Lower panel: average maximum temperature in Sydney and Melbourne over time (orange line).

Tweets containing "health advice" included three main subthemes: tweets containing general advice, such as "Have a good weekend. Don't forget the sunscreen"; tweets containing advice to sun protect at social events, such as "People going to St Kilda tomorrow, wear a hat, stay hydrated and use sunscreen"; and tweets informing the importance of sun protection because of high temperature or ultraviolet radiation index (UVI), such as "Today it's going to be hot across Australia! A reminder to slip, slop, slap, stay cool and hydrated." From the 156 tweets shared on the 25th of January about "sunscreen," "sunsmart," and "slipslopslap," approximately $25 \%$ of tweets contained warnings and information about high temperature, whereas only $8 \%$ mentioned the UVI. "Health-related expressiveness" tweets shared sun-related actions, thoughts, or feelings, such as "Hat on and sunscreen. Just drank approximately $800 \mathrm{~mL}$ of water before leaving the house"; or reported personal experiences of skin cancer, such as "Friends use sunscreen and get skin checks regularly! This is what I look like, two days after surgery to remove a Stage 1A Melanoma." From the 33 tweets shared on the 27th of January, approximately $79 \%$ contained messages about personal skin cancer experiences. 
Table 3. Example of tweets from the 2 peak days for each of the datasets

\begin{tabular}{|c|c|c|}
\hline Dataset & Peak days & Example of tweets \\
\hline Slipsloplsap & January 25 & $\begin{array}{l}\text { Today it's going to be hot across Australia! A reminder to slip, slop, slap, stay } \\
\text { cool and hydrated } \\
\text { Media for ANZJPH article on sun safety; slip, slop slap every morning } \\
\text { Slip slop slap it's going to be hot; Melbourne weather } \\
\text { The new year is usually the time we start new habits; good sun protection slows } \\
\text { the signs of ageing and prevents skin cancer! }\end{array}$ \\
\hline Sunsmart & January 25 & $\begin{array}{l}\text { Sun safety professionals now recommend individuals apply sunscreen every } \\
\text { day } \\
\text { Temperatures are going to rise this long weekend it's important to stay cool and } \\
\text { hydrated this weekend } \\
\text { Extremely hot conditions, with temperatures in the mid 40s; be sun smart, and } \\
\text { carry water with you } \\
\text { Be careful in the heat on Friday - Stay hydrated and be sunsmart }\end{array}$ \\
\hline Sunscreen & January 25 & $\begin{array}{l}\text { Maybe you are not using enough sunscreen - here's how much experts now say } \\
\text { you need } \\
\text { Hat on and sunscreen; just drank approximately } 800 \mathrm{~mL} \text { of water before leaving } \\
\text { the house } \\
\text { Have a good weekend; don't forget the sunscreen! } \\
\text { People going to St. Kilda tomorrow, wear a hat, stay hydrated and use } \\
\text { sunscreen }\end{array}$ \\
\hline Skincancer & January 27 & $\begin{array}{l}\text { Friends use sunscreen and get skin checks regularly! This is what I look like, } \\
\text { two days after surgery to remove a stage } 1 \text { A melanoma } \\
\text { Protect babies and infants; an important risk for melanoma in later life is sun } \\
\text { exposure as an infant } \\
\text { Researchers in Australia find which cells can halt the growth of melanoma cells } \\
\text { This is a good way to start the New Year with research showing how we can } \\
\text { fight melanoma }\end{array}$ \\
\hline
\end{tabular}

\section{NSCAW Campaign}

There were 108 tweets directly relating to the NSCAW campaign by 61 unique users. Of these, $65 \%$ were original tweets and 35\% retweets. The main contributors were health organisations, responsible for approximately $50 \%$ of all tweets ( $n=22$, including 10 cancer-related organisations), and individuals $(n=21)$. Regarding cancer organisations, the main contributors were the Cancer Council Australia, followed by the Cancer Council Western Australia and the SunSmart Western Australia, who contributed 8,7 , and 7 times, respectively. Other organisations and celebrities made fewer contributions ( $n=16$ and $n=$ 2 , respectively). Most tweets posted by health organisations were original tweets (approximately $70 \%$ ), while $70 \%$ of the tweets posted by individuals were retweets.

Overall, the campaign had the potential to attain approximately 2,777,370 impressions. Even though they only contributed twice, celebrities generated considerably more impressions $(n=2,093,252)$ than any other group.

\section{Most Retweeted and Liked Tweets}

Table 4 displays examples of the most retweeted and liked tweets from the datasets "slipslopslap," "sunsmart," "skincancer," and "NSCAW." Non-health-related organisations and celebrities with a high number of followers achieved a substantial number of likes and retweets. Personal experiences of skin cancer were highly retweeted and liked even if posted by individuals with a small number of followers.

\section{Discussion}

Social media has become a virtual place where individuals share experiences, interact with others, and seek information. Results show that Australians are using Twitter to communicate about their sun-related and skin cancer experiences and share information and advice on this matter. While many tweets were about personal sunscreen use $(n=5,842)$ or skin cancer $(n=3,936)$, fewer 
Table 4. Examples of the most retweeted and liked tweets

\begin{tabular}{|c|c|c|c|c|}
\hline Dataset & $\begin{array}{l}\text { Examples of most retweeted } \\
\text { tweets }\end{array}$ & Tweeted by & Examples of most liked tweets & Tweeted by \\
\hline \multirow[t]{2}{*}{ Slipslopslap } & $\begin{array}{l}\text { High temperatures are } \\
\text { expected at the Avalon } \\
\text { Airshow 2019, hydrate and } \\
\text { slip, slop, slap }\end{array}$ & Organisation & $\begin{array}{l}\text { City sunset showed } \\
\text { scintillating splendour! } \\
\text { Melbourne's Monday is } \\
\text { marked by much magnificent } \\
\text { meteorology, but such } \\
\text { wonderful sunshine sets the } \\
\text { scene for sunburn so slip, slop, } \\
\text { slap, slide and seek! }\end{array}$ & Organisation \\
\hline & $\begin{array}{l}\text { If you are planning to attend } \\
\text { AusOpen this week it would } \\
\text { serve you well to Slip, Slop, } \\
\text { Slap, Slide and Seek! Stay } \\
\text { hydrated and beware of high } \\
\text { UV levels }\end{array}$ & Organisation & $\begin{array}{l}\text { Might be a day for the beach? } \\
\text { Hot weather, stay cool } \\
\text { slipslopslap? }\end{array}$ & Celebrity \\
\hline \multirow[t]{2}{*}{ Sunsmart } & $\begin{array}{l}\text { At the moment Australia is } \\
\text { the hottest place on Earth; it's } \\
\text { now } 42 \mathrm{c} \text { and rising in } \\
\text { Melbourne with extreme UV; } \\
\text { be sun smart }\end{array}$ & Individual & $\begin{array}{l}\text { The Small Master of Sun } \\
\text { Safety }\end{array}$ & Organisation \\
\hline & $\begin{array}{l}\text { You could get a sunburn in } \\
\text { about } 10 \text { min without sun } \\
\text { protection, please be } \\
\text { SunSmart }\end{array}$ & $\begin{array}{l}\text { Individual } \\
\text { (partner of a } \\
\text { celebrity) }\end{array}$ & $\begin{array}{l}\text { This person with stage } 4 \\
\text { melanoma is running a } \\
\text { campaign to make SunSmart } \\
\text { cool through LEGO }\end{array}$ & Celebrity \\
\hline \multirow[t]{2}{*}{ Skincancer } & $\begin{array}{l}\text { Friends use sunscreen and get } \\
\text { skin checks regularly! This is } \\
\text { what I look like, two days } \\
\text { after surgery to remove a } \\
\text { stage } 1 \mathrm{~A} \text { melanoma }\end{array}$ & Individual & $\begin{array}{l}\text { I had surgery to remove a } \\
\text { melanoma from my back; } \\
\text { fortunately, we caught it early; } \\
\text { very thankful for my practice } \\
\text { which delivered a composed } \\
\text { mind as I navigated this } \\
\text { process }\end{array}$ & Individual \\
\hline & $\begin{array}{l}\text { Concerned that a mole might } \\
\text { be skin cancer? Remember the } \\
\text { ABCDEs; if you notice any of } \\
\text { these signs, talk to your } \\
\text { doctor }\end{array}$ & $\begin{array}{l}\text { Health } \\
\text { organisation }\end{array}$ & $\begin{array}{l}\text { Use sunscreen; just got a skin } \\
\text { cancer cut out of the side of } \\
\text { my face }\end{array}$ & Individual \\
\hline \multirow[t]{2}{*}{ NSCAW } & $\begin{array}{l}\text { It's National Skin Cancer } \\
\text { Action Week and we are } \\
\text { encouraging everyone to } \\
\text { OwnYourTone and embrace } \\
\text { your natural skin tone; protect } \\
\text { yourself from UV radiation } \\
\text { and abstain from tanning }\end{array}$ & Celebrity & $\begin{array}{l}\text { Loved discussing the risks of } \\
\text { skin cancer today on the TV } \\
\text { show; OwnYourTone; } \\
\text { prevention better than cure }\end{array}$ & Celebrity \\
\hline & $\begin{array}{l}\text { Wonderful day today } \\
\text { launching NationalSkinCan- } \\
\text { cerActionWeek to remind } \\
\text { about the importance of } \\
\text { sun protection to reduce } \\
\text { skincancer risk; this summer } \\
\text { embrace your natural skin } \\
\text { tone, no tan required }\end{array}$ & $\begin{array}{l}\text { Cancer } \\
\text { organisation }\end{array}$ & $\begin{array}{l}\text { Thank you to our ambassador } \\
\text { for discussing the risks of } \\
\text { skincancer and raising } \\
\text { awareness of NationalSkin- } \\
\text { CancerActionWeek }\end{array}$ & $\begin{array}{l}\text { Cancer } \\
\text { organisation }\end{array}$ \\
\hline
\end{tabular}


related to skin cancer prevention campaigns. This was also evidenced by the lower number of tweets relating to the keywords "slip slop slap" $(n=1,068)$ or "sun-smart" ( $n=1,972)$. Surprisingly, the tweet volume referring to the 2018/2019 NSCAW campaign was minimal when compared to all other datasets $(n=108)$. The results of the qualitative analysis showed that while health and skin cancer organisations actively supported the campaign, and $70 \%$ of individual tweets were retweets, those messages did not appear to reach or resonate with a large proportion of the population, similar to previous findings which also indicated that messages were mostly shared internally [26]. This is in contrast to some other studies that reported high reach of public health campaigns on Twitter. For example, Thackeray et al. [20] found a high volume of tweets about breast cancer awareness month. In the USA, nearly 1,300 tweets were shared about the "Don't Fry Day" campaign, generating above 12 million impressions, over a 5-day period [21]. This suggests that the use of social media campaigns in Twitter has, at least theoretically, the ability to fulfil its purpose and be shared by a large number of users. More comparative effectiveness research is needed to understand how to best achieve good reach within the target population using this platform [27].

The statistical analyses performed showed significant correlation and possible causality between the number of tweets shared per day and the ambient temperature, with the volume of tweets increasing significantly on days with high temperatures and less so on days with high UVI. The predominant sharing of sun protection advice on hightemperature days may contribute to the myth that sun protection is only necessary when the temperature is high. Results from the most recent National Sun Protection Survey reported a clear gap in Australians' knowledge regarding the leading causes of sunburn [28]. The report found that $24 \%$ of the interviewees believed that temperature was the main risk factor for sunburn and fewer than $10 \%$ of participants recognised that sun protection is necessary when the UVI level is 3 or higher, regardless of temperature. Previous research has shown that people receive similar amounts of personal UV radiation on cool days and hot days due to greater intentional sun exposure on days with lower temperature [29]. The results of this study provide further evidence that public health agencies need to continue efforts to improve the public's understanding of the lack of correlation between UV intensity and ambient temperature.

Another interesting finding is that for some datasets, such as "slipslopslap," a higher number of retweets and likes were achieved when posted by non-health-related organisations or celebrities. This is consistent with previous health research, which demonstrated that tweets endorsed by celebrities are more likely to be seen and shared $[20,21]$. Health and skin cancer organisations may not achieve broad reach because their number of followers is not as substantial. When analysing the NSCAW campaign, Cancer Council Australia was the account that shared the highest number of tweets; however, probably because of its limited number of followers, it did not achieve great impact. As also concluded by Thackeray et al. [20], health organisations may benefit from linking themselves with accounts with a high number of followers to reach a higher proportion of the Twitter community. The sharing of personal skin cancer experiences was one theme that seemed to have a broad reach, even if not shared by individuals with a high number of followers. These types of tweets were often highly retweeted, which indicates that they captured the public's attention. Research has already demonstrated that the sharing of one's own cancer diagnosis has the potential to enhance engagement and communication on social media [30,31].

\section{Limitations}

There is no validated data-filtering method in the literature regarding this area, and the search terms applied may not have been optimal for all datasets. Some relevant tweets may therefore have been unintentionally missed and a greater number, or different type, of tweets may have been retrieved if the search terms were changed or broadened. Although methods were applied to control the presence of unrelated tweets, some datasets were not manually checked and are likely to have a small number of tweets that do not directly refer to the intended issue, thus slightly overestimating the frequency of use. An important and well-documented limitation of research using social media data is the issue of representativeness. Users who tweet about skin cancer and sun-related behaviours may not be representative of the overall Twitter community, and Twitter users may not be representative of the offline population.

\section{Conclusion}

Due to Twitter's extensive reach and use, and its relevance to the topic of skin cancer prevention, public health professionals should consider extending its use for the communication of skin cancer-related information. The results of this study provide important insights into how 
Twitter may be used effectively for health promotion and public health messaging in the future.

Linking tweets with temperature and sharing by celebrities or non-health-related organisations and individuals with a high following can all contribute to greater spread of skin cancer and sun-related messages.

\section{Key Message}

Twitter provides insights into sun protection communication and related social media activities.

\section{Acknowledgements}

The data used in this research were collected from TrISMA with the support of QUT's Digital Observatory team, namely Dr. Marissa Takahashi, Sam Hames, and Betsy Alpert.

\section{Statement of Ethics}

Ethics approval was granted by the Queensland University of Technology Human Research Ethics Committee prior to the initiation of any data analysis (UHREC Ref. No. 1900000035). Only accounts with privacy settings allowing the broader public to have access to the content of the tweets were included in this study. Since the study only utilised data published online, no participants were approached. When quoting a tweet, tweets were slightly rephrased and mentions and hashtags were removed to prevent tweets from being identified.

\section{Disclosure Statement}

The authors have no conflicts of interest to declare.

\section{Funding Sources}

Monika Janda is funded by an NHMRC TRIP Fellowship (APP1151021)

\section{Author Contributions}

C.V.S.: quantitative and qualitative data analysis and drafting, writing, and revision of the manuscript. D.J.: statistical analysis. M.J.: writing and critical revision of the manuscript. All authors read and approved the final manuscript.

\section{References}

1 Apalla Z, Lallas A, Sotiriou E, Lazaridou E, Ioannides D. Epidemiological trends in skin cancer. Dermatol Pract Concept. 2017 Apr; 7(2):1-6.

2 World Health Organization International Agency for Research on Cancer. Cancer Today: Estimated age-standardized incidence rates (World) in 2018, melanoma of skin, both sexes, all ages [Internet]. Lyon: IARC; 2018 [cited 2019 Aug 26]. Available from: http:// gco.iarc.fr/today/online-analysismap? $\mathrm{v}=2018 \&$ mode $=$ population \&mode_pop ulation $=$ continents\&population $=900 \&$ popul ations $=900 \& \mathrm{key}=$ asr $\&$ sex $=0 \&$ cancer $=16 \&$ typ $\mathrm{e}=0$ \&statistic $=5$ \& prevalence $=0$ \&population group $=0 \&$ ages_group $\% 5 \mathrm{~B} \% 5 \mathrm{D}=0$ \&ages _ group $\% 5 \mathrm{~B} \% 5 \mathrm{D}=17 \& \mathrm{nb}$-items $=5 \&$ group cancer $=1$ \&include_nmsc $=1$ \&include_nmsc other $=1 \&$ projection =globe \& color palette $=$ default \&map_scale $=$ quantile $\&$ map nb_colors $=5 \&$ continent $=0 \&$ rotate $=\% 255 \mathrm{~B} 10$ $\% 252 \mathrm{C} 0 \% 255 \mathrm{D}$.

3 Australian Institute of Health and Welfare. Cancer in adolescents and young adults in Australia [Internet]. Canberra: AIHW; 2018 [cited 2019 Aug 26]. Cat. No. CAN 110. Available from: https://www.aihw.gov.au/getmedia/ ed22109b-ab23-4273-8d23-7949a8922ea2/aihw-can-110.pdf.aspx?inline=true.
4 Montague M, Borland R, Sinclair C. Slip! Slop! Slap! and SunSmart, 1980-2000: skin cancer control and 20 years of populationbased campaigning. Health Educ Behav. 2001 Jun;28(3):290-305.

5 Koch S, Pettigrew S, Hollier LP, Slevin T, Strickland M, Minto C, et al. Trends in Australian adolescents' sun-protection behaviours: implications for health campaigns. Aust N Z J Public Health. 2016 Oct;40(5): $468-73$.

6 Volkov A, Dobbinson S, Wakefield M, Slevin T. Seven-year trends in sun protection and sunburn among Australian adolescents and adults. Aust N Z J Public Health. 2013 Feb; 37(1):63-9.

7 Williams M, Jones SC, Caputi P, Iverson D. Australian adolescents' compliance with sun protection behaviours during summer: the importance of the school context. Health Promot Int. 2012 Mar;27(1):15-22.

8 We are social, Hootsuite. Global digital report 2018 [Internet]. Sydney: We are social; 2018 [cited 2019 Sep 3]. Available from: https:// digitalreport.wearesocial.com/.

9 Sensis. The must-know stats from the 2018 yellow social media report [Internet]. Melbourne: Sensis; 2018 [cited 2019 Sep 10]. Available from: https://www.sensis.com.au/ about/our-reports/sensis-social-media-report.
10 Weller K, Bruns A, Burgess J, Mahrt M. C. P. Twitter and society: an introduction. In: Weller K, Bruns A, Burgess J, Mahrt M, Puschmann C, editors. Twitter and society. New York: Peter Lang; 2015. pp. xxix-xxxviii.

11 Li Y, Wang X, Lin X, Hajli M. Seeking and sharing health information on social media: a net valence model and cross-cultural comparison. Technol Forecast Soc Change. 2018 Jan; 126:28-40.

12 Thackeray R, Crookston BT, West JH. Correlates of health-related social media use among adults. J Med Internet Res. 2013 Jan; 15(1):e21

13 Moorhead SA, Hazlett DE, Harrison L, Carroll JK, Irwin A, Hoving C. A new dimension of health care: systematic review of the uses, benefits, and limitations of social media for health communication. J Med Internet Res. 2013 Apr;15(4):e85.

14 Yonker LM, Zan S, Scirica CV, Jethwani K, Kinane TB. "Friending" teens: systematic review of social media in adolescent and young adult health care. J Med Internet Res. 2015 Jan; 17(1):e4.

15 Eysenbach G. Infodemiology and infoveillance: framework for an emerging set of public health informatics methods to analyze search, communication and publication behavior on the Internet. J Med Internet Res. 2009 Mar;11(1):e11. 
16 Chew C, Eysenbach G. Pandemics in the age of Twitter: content analysis of Tweets during the 2009 H1N1 outbreak. PLoS One. 2010 Nov;5(11):e14118.

17 Ghosh DD, Guha R. What are we 'tweeting' about obesity? Mapping tweets with Topic Modeling and Geographic Information System. Cartogr Geogr Inf Sci. 2013;40(2):90102.

18 Kim E, Hou J, Han JY, Himelboim I. Predicting retweeting behavior on breast cancer social networks: network and content characteristics. J Health Commun. 2016;21(4):47986.

19 Lenoir P, Moulahi B, Azé J, Bringay S, Mercier G, Carbonnel F. Raising awareness about cervical cancer using Twitter: content analysis of the 2015 \#SmearForSmear campaign. J Med Internet Res. 2017 Oct;19(10):e344.

20 Thackeray R, Burton SH, Giraud-Carrier C, Rollins S, Draper CR. Using Twitter for breast cancer prevention: an analysis of breast cancer awareness month. BMC Cancer. 2013 Oct; 13(1):508
21 Nguyen JL, Heckman C, Perna F. Analysis of the Twitter "Don't Fry Day" Campaign. JAMA Dermatol. 2018 Aug;154(8):961-2.

22 Kim H, Jang SM, Kim S-H, Wan A. Evaluating sampling methods for content analysis of Twitter data. Soc Media Soc. 2018 Apr;4(2). Available from: https://doi org/10.1177/2056305118772836.

23 Murton D. How Australians use Twitter [Internet]. Brisbane: Marginmedia; 2013 [cited 2019 Sep 13]. Available from: http://blog. marginmedia.com.au/Our-Blog/bid/97171/ How-Australians-Use-Twitter.

24 Australian Government Bureau of Metereology. Climate data online [Internet]. 2019 [cited 2019 Aug 6]. Available from: http://www. bom.gov.au/climate/data/index. shtml?bookmark $=200 \& v i e w=$ map.

25 Thomas DR. A general inductive approach for analysing qualitative evaluation data. Am J Eval. 2006 Jun;27(2):237-46.

26 Park H, Reber BH, Chon MG. Tweeting as health communication: health organizations' use of Twitter for health promotion and public engagement. J Health Commun. 2016; 21(2):188-98.
27 Freeman B, Potente S, Rock V, McIver J. Social media campaigns that make a difference: what can public health learn from the corporate sector and other social change marketers? Public Health Res Pract. 2015 Mar; 25(2):e2521517.

28 Cancer Council Australia. 9 in 10 Australians don't know when they need sun protection [Internet]. 2019 [cited 2019 Sep 10]. Available from: https://www.cancer.org.au/news/media-releases/9-in-10-australians-dont-knowwhen-they-need-sun-protection.html.

29 Neale RE, Hamilton AR, Janda M, Gies P. Green AC. Seasonal variation in measured solar ultraviolet radiation exposure of adults in subtropical Australia. Photochem Photobiol. 2010 Mar-Apr;86(2):445-8.

30 Noar SM, Leas E, Althouse BM, Dredze M, Kelley D, Ayers JW. Can a selfie promote public engagement with skin cancer? Prev Med. 2018 Jun;111:280-3.

31 Wang X, Chen L, Shi J, Peng TQ. What makes cancer information viral on social media? Comput Human Behav. 2019 Apr;93:149-56. 